\title{
Optimal Learning Controller Design Using Particle Swarm Optimization: Applied to CSI System
}

\author{
Khulood Moosa Omran*, Abdul-Basset A. Al- Hussein, Basil Hani Jassim \\ Electrical Engineering Department, Basrah University, Basrah, Iraq
}

\author{
Correspondence \\ *Khulood Moosa Omran \\ Electrical Engineering Department, \\ Basrah University, Basrah, Iraq \\ Email: khuldomrn2010@gmail.com; \\ khulood.omran@uobasrah.edu.iq
}

\begin{abstract}
In this article, a PD-type iterative learning control algorithm (ILC) is proposed to a nonlinear time-varying system for cases of measurement disturbances and the initial state errors. The proposed control approach uses a simple structure and has an easy implementation. The iterative learning controller was utilized to control a constant current source inverter (CSI) with pulse width modulation (PWM); subsequently the output current trajectory converged the sinusoidal reference signal and provided constant switching frequency. The learning controller's parameters were tuned using particle swarm optimization approach to get best optimal control for the system output. The tracking error limit is achieved using the convergence exploration. The proposed learning control scheme was robust against the error in initial conditions and disturbances which outcome from the system modeling inaccuracies and uncertainties. It could correct the distortion of the inverter output current waveform with less computation and less complexity. The proposed algorithm was proved mathematically and through computer simulation. The proposed optimal learning method demonstrated good performances.
\end{abstract}

Keyword: Learning control, PD feedback, PSO, CSI.

\section{INTRODUCTION}

Learning control system is a control system that has the ability to learn. The term 'learning control' was frequently used with other words such as the 'betterment process', 'iterative control' and 'repetitive control' to refer exactly to the same thing. The idea is to apply a simple algorithm repetitively to an unknown plant system until perfect tracking is achieved. It evolves the performance by repeating the operation.

The first scheme of learning control algorithm was suggested in 1984 by Arimoto et al. [1]. It stands for the repeat ability of operation and prospect of developing the input value on the base of measurement data at the previous operation, no accurate description of dynamics for system under control is required for construction of the learning algorithm. So the proposed technique can face the nonlinearity of the system under control [2]. Later Arimoto et al. [3-5] developed the concept and actively presented their works in a number of published articles.

The learning control algorithms are used for control the robot manipulators in many applications [6-17]. In this article, learning control theory is utilized by developing a controller for (CSI) current-source PWM inverter. The proposed learning control algorithm was enhanced with PSO as an optimal approach to tune the gain parameters of the controller.

\section{LEARNING CONTROL METHOD}

The learning controller aims to improve the control command input of the system $u_{n}(t)$ to generate an output signal $y(t)$ that track a given desired output $y_{d}(t)$, through a fixed time duration. The basic method of iterative learning control can be seen in Fig. (1). The learning control input vector $u_{n}(t)$ and the output vector $y(t)$ are saved in memory at each time when the system model activates. The symbol $k$ refers to the trial number while $t$ is the time variable. The error performance is $E_{k}(t)=y_{k}(t)-y_{d}(t)$, where the desired output of the system is $y_{d}(t)$. Then the learning controller function determines a new command input signal $u_{n}^{k+1}(t)$ which using the error signal, and saved for the next iteration. The next input command is chosen to guarantee that the error performance will be gradually decreasing on the next iteration. 


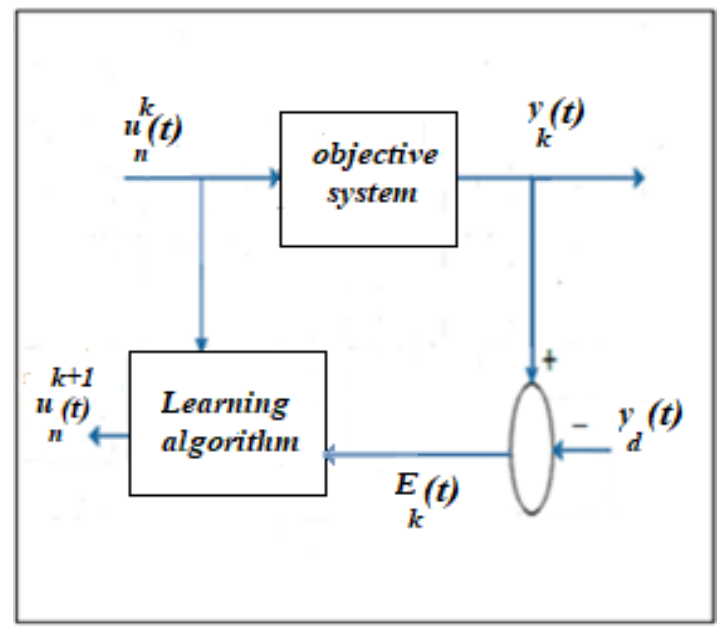

Fig. 1: Basic iterative learning control scheme

\section{The Current SOURCE INVERTER MODEL}

The current source inverter (CSI) model is utilized in the applications of high-power, which has an input source of dc constant current that is readily available, such as in the medium voltage ac drive with a controlled rectifier and super conducting magnetic energy storage [18]. In these applications, the main reason for utilizing a CSI was its essential bidirectional action, a smoother set of output voltage waveforms appropriate to operative ac motors without causing excessive insulation stress, and short-circuit protection [19].

The function of CSI is to transform the continuous dc input voltage into alternative output current. The inverter which gives constant output current gives high dynamic performance for ac drive [20]. In the last years, there has been a wide interest to the control of CSI [21 - 26]. There are several types of controllers that actively control the output of the inverter along the entire waveform. The most widely used technique for current control is the hysteresis current controllers which are also called instantaneous feedback current controllers [24].

In this technique, the switching frequency varies during the fundamental period and may exceed the inverter switching devices limits at certain conditions. To overcome this problem, band hysteresis and adaptive hysteresis are used. These techniques will not completely solve this problem although they complicated the design of the inverter. In this article, PWM constant current controller is proposed through the use of the ILC theory and enhanced by PSO optimal approach.

The learning controller can compensate and correct the distortion of the inverter output current waveform due to load variations, disturbances and nonlinear load conditions with less computation and less complexity, which led to decrease the cost of the controller.

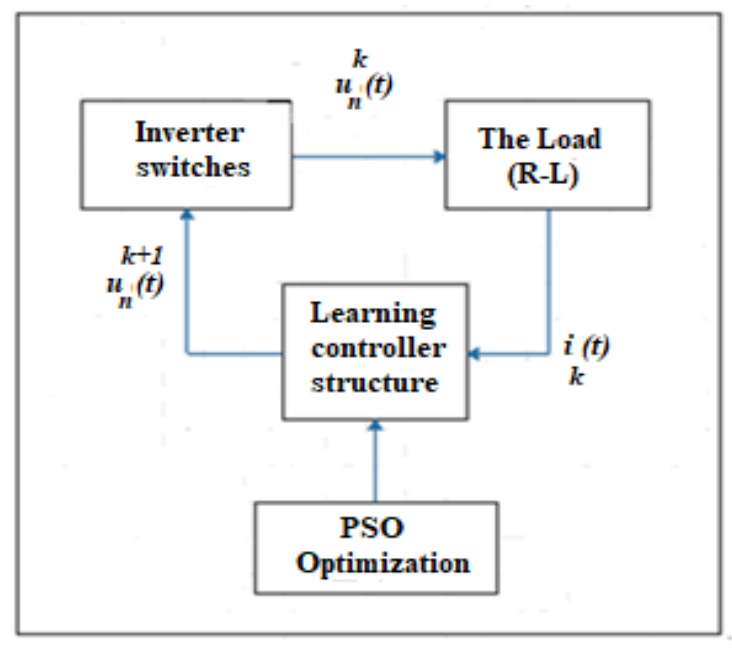

Fig. 2: The system model.

\section{THE SYSTEM MODEL}

A general block diagram for learning controller of current source pulse width modulation inverter was indicated in Fig. (2). The bridge inverter and R-L load are used as the system plant of a closed loop digital feedback system. The closed loop system measures the output current $i_{k}(t)$ to make the inverter tracks a given reference current. The learning controller controls the inverter switches to make the output current track the desired sinusoidal reference signal.

The required pulse width is calculated by using learning control algorithm. The input control signal to the inverter switches is updated by the actual output measured current at the previous trail and desired reference output. The objective system refers to inverter with R-L load. To allow the inverter output current to approach the desired one in each trail, input control signal to the inverter switches was obtained by the output measured current at the previous trail and reference one.

The input PWM signal given to the inverter switches is modified by the data of the real output current at the previous trail of the sinusoidal period and updated iteratively, the trajectory tracking error $E_{k}$, is gradually decreasing and with learning progresses it will converge to zero. The output current tracks the predefined trajectory. The dynamics of such a current-source PWM inverter with R-L load can be described in the following:

$$
\begin{gathered}
u_{n}(t)=L x_{2}(t)+\left(R+R_{S}\right) x_{1}(t) \\
y(t)=R_{S} x_{1}(t)
\end{gathered}
$$

with

$$
\begin{gathered}
{\left[x_{1}(t) x_{2}(t)\right]=\left[i_{k}(t) \dot{i_{k}}(t)\right]} \\
\dot{x}_{1}(t)=x_{2}(t)
\end{gathered}
$$




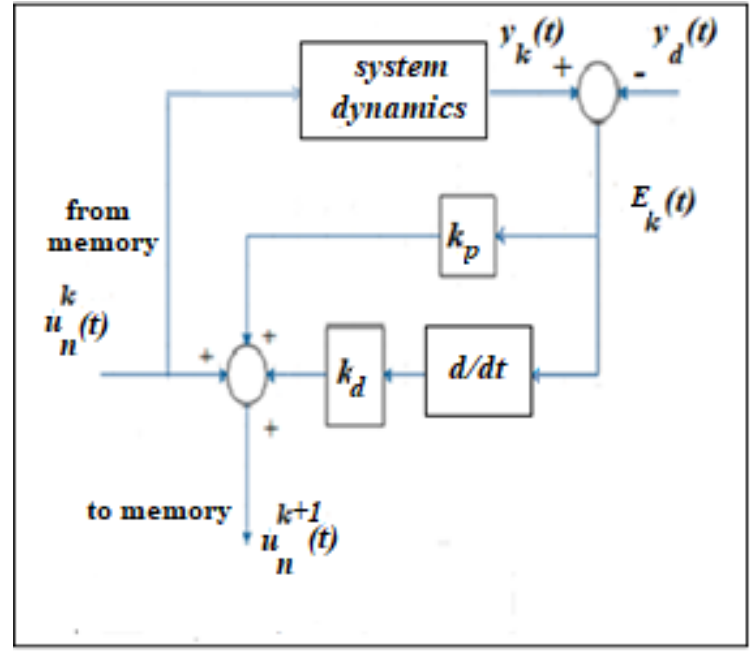

Fig. 3: PD type learning control.

$$
\dot{x}_{2}(t)=-\left(R+R_{S}\right) x_{1}(t)+1 / L u_{n}(t)
$$

Where $R_{S}$ is the current sensing resistor, and $y(t)$ is the output sensing current. This frame work of learning control which is shown in Fig. (1), postulates the following conditions [4]:

1. For each process of the system it has a fixed period of time, $\mathrm{T}>0$.

2. A desired reference output signal $y_{d}(t)$ is priori known for the time period $t \in[0, T], y_{d}(t+T)=y_{d}(t)$.

3 . The initial condition at every iteration is fixed, the initial state $x_{\mathrm{k}}(t)$ can be defined at the beginning of each iteration as:

$x_{k}(0)=x_{0}$ for $k=1,2,3, \ldots$

4. The parameters of the system are slowly changed with time and can be approximated to be fixed during learning time.

5. The next command input signal $u_{n}^{k+1}(t)$ must be composed of a simple and fixed recursive law as follows:

$$
u_{n}^{k+1}(t)=f\left[u_{n}^{k}(t), E^{k}(t)\right]
$$

The input command signal $u_{n}(t)$ and the output trajectory tracking signal $y_{k}(t)$ are saved in memory each time the system operates. The symbol $k$ refers to the trail ILC algorithm then determine the error between the measured actual output and the desired reference signal, $E_{k}(t)=$ $y_{k}(t)-y_{d}(t)$, where $y_{d}(t)$ is the reference desired output trajectory of the system. The suggested PD learning algorithms utilized in this article are as indicated below $[3,11]$ :

$$
u_{n}^{k+1}(t)=u_{n}^{k}(t)-\left(k_{p}+k_{d} d / d t\right) E_{k}(t)
$$

The PD learning control function generate a new input signal $u_{n}^{k+1}(t)$, that is saved in the memory to utilize on the next iteration, The next updated command input is chosen to guarantee that the error between real and desired reference output signal will be gradually decreasing on the next iteration. The signal, $E_{k}(t)$ is the present error signal as shown in Fig. $3, k_{p}, k_{d}$ are learning gains that employed as learning parameters. In the following section, the convergence proof is given.

\section{The Convergence Proof}

In this section, the mathematical proof of stability and convergence was developed for PD type learning controller. The switching PWM signal is shown in Fig. (4). It indicates one sample of the PWM pattern, with $n$ the pulse width of the PWM pattern, $t_{d}$ is the time duration of one sample pulse. $v$ is the amplitude of the pulse. The equivalent control signal for input $u_{n}(t)$ is shown below [21]:

$$
\begin{gathered}
u_{n}^{k}(t)=\left[n v-v\left(t_{d}-n\right)\right] / t_{d} \\
\Delta u_{n}^{k}(t)=2 v / t_{d}\left(n_{k}(t)-n_{d}(t)\right) \\
\Delta u_{n}^{k}(t)=2 v / t_{d}\left(\Delta n_{k}(t)\right) \\
\Delta n_{k}(t)=t_{d} / 2 v\left(\Delta u_{n}^{k}(t)\right)
\end{gathered}
$$

the proposed developed learning control algorithm is as indicated below:

$$
\begin{aligned}
& n_{k+1}(t)=n_{k}(t)-k_{p}\left[i_{k}(t)-i_{d}(t)\right]-k_{d}\left[\dot{i_{k}}(t)-\right. \\
& \left.\dot{i_{d}}(t)\right]
\end{aligned}
$$

Let $n_{d}(t)$ is the pulse width that yields the desired current signal $i_{d}(t)$ which have to be generated through update of $n_{k}(t)$ so that $n_{k}(t) \rightarrow n_{d}(t)$ for $t \in[0, T]$, and load current $i_{k}(t)$ generated by this control input are such that $\left\|\Delta i_{k}(t)\right\| \longrightarrow 0$ for all $t \in[0, T]$. Subtracting $n_{d}(t)$ from both sides of (12)

$n_{k+1}-n_{d}=n_{k}-n_{d}-k_{p}\left(i_{k}-i_{d}\right)-k_{d}\left(\dot{i_{k}}-\dot{i_{d}}\right)$

then

$$
\Delta n_{k+1}=\Delta n_{k}-k_{p} \Delta i_{k}-k_{d} \Delta \dot{i_{k}}
$$

where

$$
\Delta n_{k+1}=n_{k+1}-n_{d}
$$

Then each side were squared and multiplied by $\left(1 / k_{p}\right)$ yields:

$1 / k_{p}\left(\Delta n_{k+1}\right)^{2}=1 / k_{p}\left(\Delta n_{k}-k_{p} \Delta i_{k}-k_{d} \Delta i_{k}\right)^{2}$ 


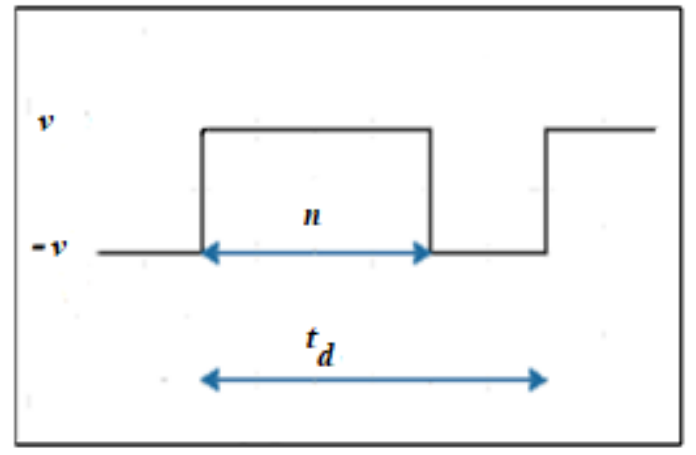

Fig. 4: PWM Signal

$k_{p}{ }^{-1} \Delta n_{k+1}^{2}=k_{p}^{-1} \Delta n_{k}{ }^{2}-2 \Delta i_{k} \Delta n_{k}-$

$2 k_{p}^{-1} k_{d} \Delta i_{k} \Delta n_{k}+k_{p} \Delta i_{k}{ }^{2}+$

$k_{p}{ }^{-1} k_{d}^{2} \Delta{\dot{i_{k}}}^{2}+2 k_{d} \Delta i_{k} \Delta i_{k}$

Then by Integrate each side of (17) for the time $[0, \mathrm{~T}]$ yields:

$\int_{0}^{T} k_{p}{ }^{-1} \Delta n_{k+1}^{2} d t=\int_{0}^{T} k_{p}{ }^{-1} \Delta n_{k}^{2} d t-$

$2 \int_{0}^{T} \Delta i_{k} \Delta n_{k} d t-2 \int_{0}^{T} k_{p}{ }^{-1} k_{d} \Delta i_{k} \Delta n_{k} d t+$

$\int_{0}^{T} k_{p} \Delta i_{k}^{2} d t+\int_{0}^{T} k_{p}{ }^{-1} k_{d}{ }^{2} \Delta i_{k}^{2} d t+$

$2 \int_{0}^{T} k_{d} \Delta i_{k} \Delta i_{k} d t$

Define a norm function as:

$$
\left\|\Delta n_{k}\right\|=\left\|\int_{0}^{T} k_{p}^{-1} \Delta n_{k}^{2} d t\right\|^{1 / 2}
$$

Then (18) in terms of $\mathrm{L}^{2}$-norm can be given as:

$\left\|\Delta n_{k+1}\right\|^{2}=\left\|\Delta n_{k}\right\|^{2}+\left\|k_{d} \Delta i_{k}\right\|^{2}+\left\|k_{d} \Delta i_{k}\right\|^{2}-$ $2 \int_{0}^{T} \Delta i_{k} \Delta n_{k} d t-2 \int_{0}^{T} k_{d} k_{p}{ }^{-1} \Delta i_{k} \Delta n_{k} d t+$

$2 \int_{0}^{T} k_{d} \Delta i_{k} \Delta \dot{i_{k}} d t$

If the product of $\Delta n_{k}$ with $\Delta i_{k}$ or with $\Delta \dot{i_{k}}$ is positive always and achieves the margin that gives compensation for

$\left\|k_{p} \Delta i_{k}\right\|^{2}+\left\|k_{d} \Delta i_{k}\right\|^{2}$ in (20) or if the inequality:

$2 \int_{0}^{T} \Delta i_{k} \Delta n_{k} d t+2 \int_{0}^{T} k_{d} \cdot k_{p}^{-1} \Delta k_{d} \Delta n_{k} d t-$

$2 \int_{0}^{T} k_{d} \Delta i_{k} \Delta \dot{i_{k}} d t>(1+\gamma)\left[\int_{0}^{T} k_{p} \Delta i_{k}^{2} d t\right.$

$\left.+\int_{0}^{T} k_{d}^{2} k_{p}^{-1} \Delta{\dot{i_{k}}}^{2} d t\right]$

$=(1+\gamma)\left(\left\|k_{p} \Delta i_{k}\right\|^{2}+\left\|k_{d} \Delta \dot{i}_{k}^{2}\right\|\right)$

Then with a positive constant $\gamma$, we obtain from (20) the following inequality [21]:

$\left\|\Delta n_{k+1}\right\|^{2}<\left\|\Delta n_{k}\right\|^{2}-\gamma\left\|k_{p} \Delta i_{k}\right\|^{2}-\gamma\left\|k_{d} \Delta \dot{i_{k}}\right\|^{2}$ which means that the input error in the pulse width is decreasing with repeated trails, since the sequence $\left\|\Delta n_{\mathrm{k}}\right\|$ is bounded and gradually decreased with learning progress as long as $\left\|\Delta i_{k}\right\|$ does not vanish, then monotonously decrease of $\left\|\Delta n_{\mathrm{k}}\right\|$ means the convergence which satisfies that

$$
\left\|k_{p} \Delta i_{k}\right\|^{2}+\left\|k_{d} \Delta \dot{i_{k}}\right\|^{2} \rightarrow 0
$$

as $k \rightarrow \infty$ This means that $\left\|\Delta i_{k}\right\| \rightarrow 0$ and $\left\|\Delta i_{k}\right\| \rightarrow$ 0 as $k \rightarrow \infty$ which implies the convergence of learning law. From (20) in order to ensure the convergence condition the term $[5,21]$ :

$$
\int_{0}^{T} \Delta n_{k} \Delta i_{k} d t>0
$$

Then the principle condition for convergence is the left side of inequality (23) should be positive, which means the system under control satisfies the passivity property. Then by using (11) and the condition of (23) yields:

$$
\left(t_{d} / 2 v\right) \int_{0}^{T} \Delta u_{n}^{k}(t) \Delta i_{k} d t>0
$$

the system dynamics must satisfy the passivity with respect to the output current to the input signal, the system is said to be strictly passive if

$$
\int_{0}^{T} u_{n}^{k} i_{k} d t>\eta \int_{0}^{T} i_{k}^{2} d t+\mathrm{c}
$$

Where $\eta>0$ and $\mathrm{c}$ is a constant [21]. Then by using (1) and (2) we get

$$
\begin{aligned}
& \int_{0}^{T} u_{n}^{k}(t) y_{k} d t=\int_{0}^{T} R_{S} i_{k}\left(L \frac{d i_{k}}{d t}\left(R+R_{S}\right) i_{k}\right) d t \\
& =\int_{0}^{T} R_{S}\left(\left(R+R_{S}\right) i_{k}^{2}+i_{k}\left(L \frac{d i_{k}}{d t}\right)\right) d t \\
& =R_{S}\left[\int_{0}^{T} i_{k}^{2}\left(\left(R+R_{S}\right) d t+L \int_{i(0)}^{i(T)} i_{k} d i_{k}\right]\right. \\
& =R_{S}\left(\mathrm{R}+R_{S}\right) \int_{0}^{T} i_{k}^{2} d t+\frac{1}{2} L R_{S}\left[i_{k}^{2}(T)-i_{k}^{2}(0)\right]
\end{aligned}
$$

Since $i_{k}^{2}(\mathrm{~T})$ is always positive, (27) can match (26) with $\eta$ and $c=1 / 2 L . R_{S} i_{k}^{2}(0)$ which proves the passivity of the system. The performance of PD learning controller indicated in (7) is depending on $k_{p}$ the proportional gain, and $k_{d}$ the derivative gain. The particle swarm optimization (PSO) algorithm is utilized in this article which has convergent result and not required much iterations to get optimal values of $k_{p}$ and $k_{d}$.

\section{Particle Swarm Optimization (PSO)}

PSO is one of the bio-searching approaches utilized for many applications [27]. It was proposed by Kennedy and Eberhard. PSO utilized a suitable model based on the social interaction between, independent particles and it uses swarm knowledge in order to get the optimal solution of the global maximum or minimum of a generic function. It depended on the behavior of individuals such as particles or agents of a swarm. 
In the PSO approach the experience accumulated during the evolution is utilized to find the optimal solution [28]. In every iteration, the particle moves depending on its velocity $v e_{i}$ and the fitness function to be optimized and determined for each particle in the swarm with regard to their current position. The best fitness ever reached by the swarm is the global optimum value. The modified velocity $v e_{i}^{k+1}$ and position $p s_{i}^{k+1}$ of each particle can be determined utilizing the current velocity and the position for pbest and gbest as indicated in the following equations:

$$
\begin{gathered}
v e_{i}^{k+1}=h^{k} v e_{i}^{k}+\phi_{1} \alpha_{1, i}^{k}\left(\text { pbest }_{i}^{k}-p s_{i}^{k}\right)+ \\
\phi_{2} \alpha_{2, i}^{k}\left(\text { gbest }_{i}^{k}-p s_{i}^{k}\right) \\
p s_{i}^{k+1}=p s_{i}^{k}+v e_{i}^{k+1} \Delta t s
\end{gathered}
$$

with $k$ is the number of the current iteration, $i$ is the particle's index, $h$ is a factor of friction, $\phi_{1}$, and $\phi_{2}$ are the social and cognitive constants whereas $\alpha_{1}$ and $\alpha_{1}$ are positive random numbers with a uniform distribution between 0 and 1,pbest refers to the $\mathrm{b}$ est position seen by each particle, gbest is best positi on seen by whole flock, $v e_{i}$ is the velocity of current particle, $p s$ is the current, position of particle, and $\Delta t s$ is the step time that is equal to 1 . As initially established, $h$ frequently decreases linearly between about 0.9 to 0.4 through a run. Generally, the inertia weight is set depending to the subsequent equation:

$$
h=h_{\max }-\left(h_{\max }-h_{\min } / i t r_{\max }\right) . i t r
$$

with $i t r_{\max }$ is the number of maximum iterations and itr is the number of current iteration [29]. The particle swarm optimization has the following steps which are described as follows [28,29]:

1. Initialization the flock of particles with random values for the positions and the velocities.

2. Determine the value of fitness for each element in the flock.

3. The fitness for each particle is compared with its previous best fitness (pbest) which was obtained in every iteration.

4. Check if the present value is better than pbest, then exchange pbest with the present value so that the pbest location equal to the current location in the space.

5 . The values of pbest of elements are compare then set the swarm global best location with the highest fitness (gbest).

6 . Update the value of velocity and the value of position for each particle in swarm depending to equations (28) and (29) respectively.

7. The steps from (1) to (6) is repeated until the convergence achieved. Fig. (5), shows the general flow chart of the PSO algorithm.

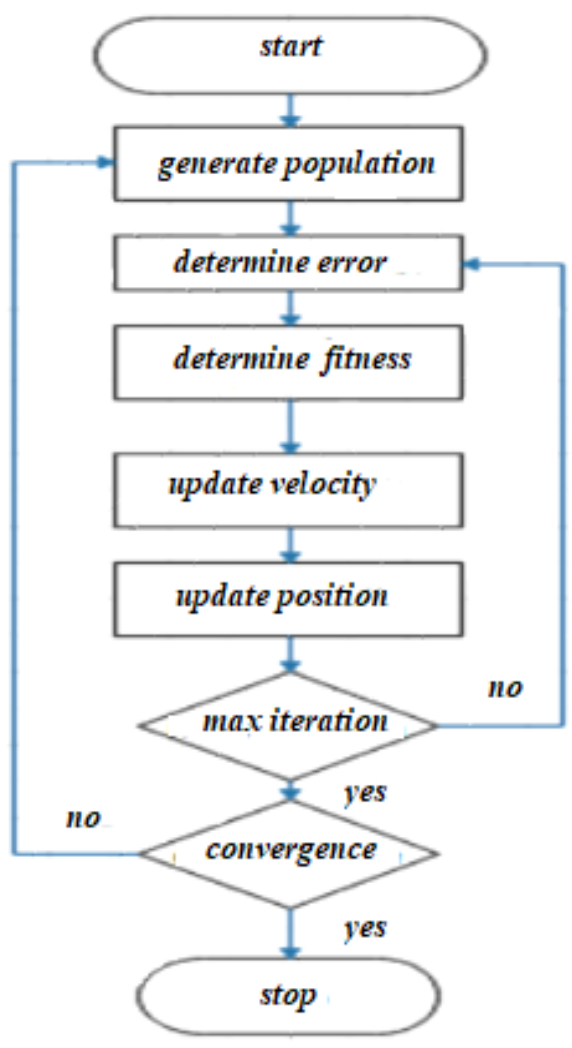

Fig. 5: PSO algorithm flow chart.

\section{SiMULATION RESULTS}

A digital computer simulation was carried out for the current source PWM inverter system controlled by learning control under linear load and studies the performance. It is assumed that the inverter operates with +1 and -1 p.u dc voltage supply. The reference sin wave is 1 p.u amplitude and frequency.

The sampling frequency is $30 \mathrm{p} . \mathrm{u}$. The load resistor is $1 \mathrm{p} . \mathrm{u}$, load inductor 0.1 p.u. To show the performance operation of the proposed controller, we apply at starting arbitrary initial pulses to the inverter switching. The design structures are suggested to get best performance by comparing the tracking of the error values for the learning control scheme defined in (7).

The classic learning PD algorithm is applied without optimal method as shown in Fig. (6), then Fig. (7) shows the effectiveness of the PD-PSO proposed method with assuming that there is no load variation. The PSO parameter 's values which are utilized to get the characteristics of the PD-PSO controller are: the size of population is $50 ; h$ equal 0.6 ; with the values of $\varnothing 1$ and $\varnothing 2$ equal to 1.2 and the iteration numbers is 100 .

The gain values of $k_{p}$, and $k_{d}$ which are calculated depending to the best optimal solution obtained with PSO, are utilized to find the system's output when there is a load variations and a disturbance effect in the reference output on the first trail.

The simulation purpose is to develop the controller's efficiency which is utilized two types of controller, classic 
PD and PD-PSO controller. The optimal parameters obtained for PD-PSO, $k_{p}=100.2, k_{d}=0.0037$. The performance index is evaluated by using the following equation [9]:

$$
M S E=\frac{1}{N} \sum_{i=1}^{N} E_{i}^{2}
$$

Where $i$ denote the step number and the total steps number is $N$. The output performance with tracking error and performance index for each case is shown in table1.

It shows the mean squared error (MSE) for the algorithm at the sixth trial. The simulation results highlight the main feature behind the schemes proposed in this work for each case problem, and it indicates that the PD-PSO leaning control algorithm gives faster performance compared with the other cases.

The robustness of the algorithms against disturbance and modeling inaccuracy is studied through computer simulation. A load parameter variation is checked when the load is increasing by $20 \%$ during steady state. Fig. (8) shows how the error is minimized and approached to zero.

A disturbance is applied to the PD-PSO system by reducing the input dc voltage by $15 \%$ as shown in Fig. (9) which indicates that the system can face this sudden disturbance and compensate it. Simulation results showed that the inverter output would be in phase and very adjacent to the desired reference of sinusoidal signal.

Any deviance of the output signal value from the reference signal value which produced by the load disturbances or nonlinear load variation could be compensated. The learning recursive law minimize the computation time which affect the maximum allowable pulse width. In these examples, the learning control gains are set the same as the previous two examples.

\section{CONCLUSIONS}

In this paper, learning control theory is employed to control current source PWM inverter so that the switching signal is

Table 1

Comparison of ILC algorithms using MSE at the sixth trail.

\begin{tabular}{ccc}
\hline \hline PD controller & $\begin{array}{c}\text { Performance } \\
\text { Index }\end{array}$ & $\begin{array}{c}\text { Performance } \\
\text { Index with PSO }\end{array}$ \\
\hline \hline $\begin{array}{c}\text { Classic type } \\
\text { The case with } \\
\text { source disturbance }\end{array}$ & $1.33 \mathrm{E}-05$ & $1.20 \mathrm{E}-05$ \\
$\begin{array}{c}\text { The case with load } \\
\text { variation }\end{array}$ & $5.05 \mathrm{E}-03$ & $1.28 \mathrm{E}-04$ \\
\hline \hline
\end{tabular}

determined and improved with the repeated trails. To achieve the control of the inverter output, the input pulses of inverter switches are modified in every trail depending on the difference between the output measurement signal and the desired one.
A PD learning controller enhanced with PSO method is achieved. To get the optimal gain values of the PD learning controller design of a CSI, the computer simulation results indicated that an optimized output response is given with a good performance for the case with optimal PD-PSO controller.

The simulation results indicated that the proposed control structure can achieve an effective exploration for the optimal PD controller gains. From the comparison of results obtained, it was shown that the PD-PSO learning control method can develop the response of scheme dynamic in a better manner.

Simulation results show the ability of the system to improve its performance on the previous operation as the action is repeated under load variations.

The presented results illustrate the effectiveness of the controller when disturbances and load variation are presented in the system. Many digital controllers cannot face and compensate the characteristic load variations, where they need to identify the parameters on line which complicates the control structure while the learning controller can overcome this problem.

The controller needs less calculations which minimizing the complexity and cost. The proposed controllers are new class of microprocessor applications to power conversion technique.

\section{CONFLICT OF INTEREST}

The authors have no conflict of relevant interest to this article.

\section{REFERENCES}

[1] S. Arimoto, S. Kawamura and F. Miyazaki,"Bettering operation of robots by learning " J. Robotics System, vol. 1, no.2, pp. 123-140, 1984.

[2] K.L. Moore "Iterative Learning Control for Deterministic Systems", Springer, Verlag London Limited, 2012.

[3] S. Arimoto and T. Naniwa," Learning control theory for robotic systems" Int. J. of adaptive control and signal proc. vol.4, no.6, pp. 453-465, July, 1990.

[4] S. Arimoto, "Passivity and Learn ability for mechanical systems, a learning control theory for skill refinement" IEICE Trans. vol. E75, no.5, pp. 552-560, May 1992.

[5] S. Arimoto and T. Naniwa, "A quasi - natural potential that gives rise to learnability and Adaptability in robotic systems", J. of systems Engineering, no.1, vol. 5, p. p 163 173, 1995.

[6] R. Ma, and G. Zhang, "Iterative learning tracking control for a class of MIMO nonlinear time-varying systems", vol.27, Issue 4, June 2017.

[7] T. Meng, and Wei H," Iterative learning control for flexible structures", Beijing and Springer,2020.

[8] D. H. Owens," Iterative learning control: An optimization Paradigm", Springer, pp186-187, April, 2017. 


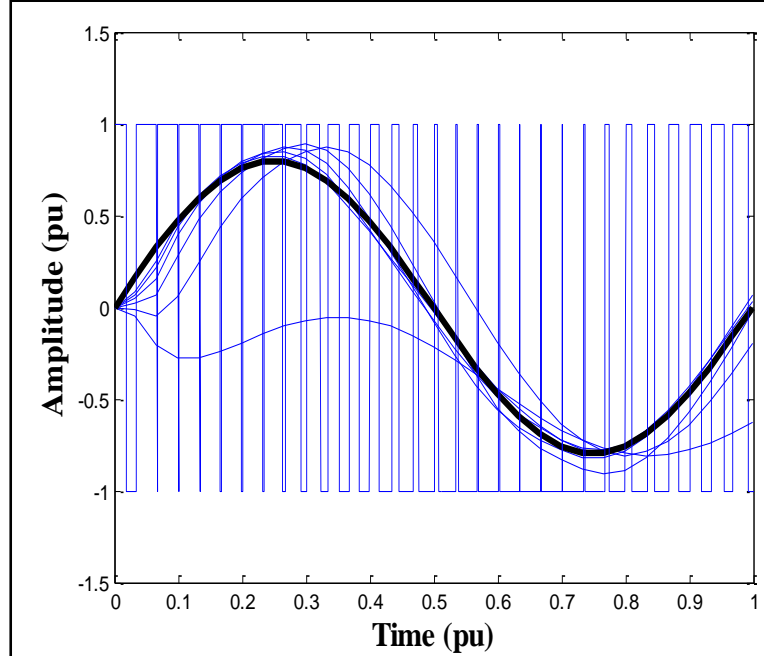

(a)

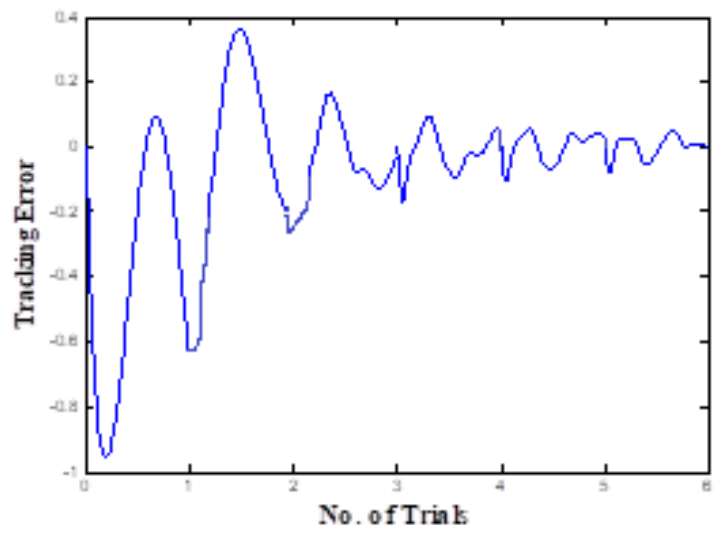

(b)

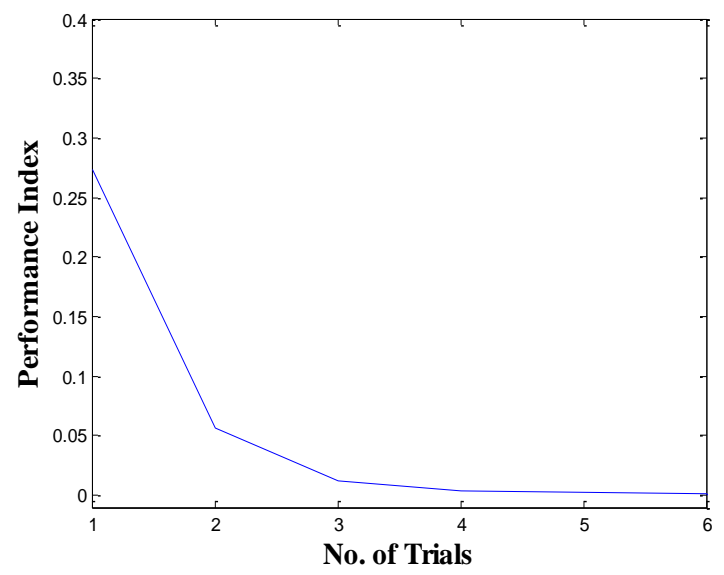

(c)

Fig. 6: Classic PD-type learning algorithm without optimal gain: (a) $i_{k}(t), i_{d}(t)$ with switching signal, (b) Tracking error, (c) The performance index.

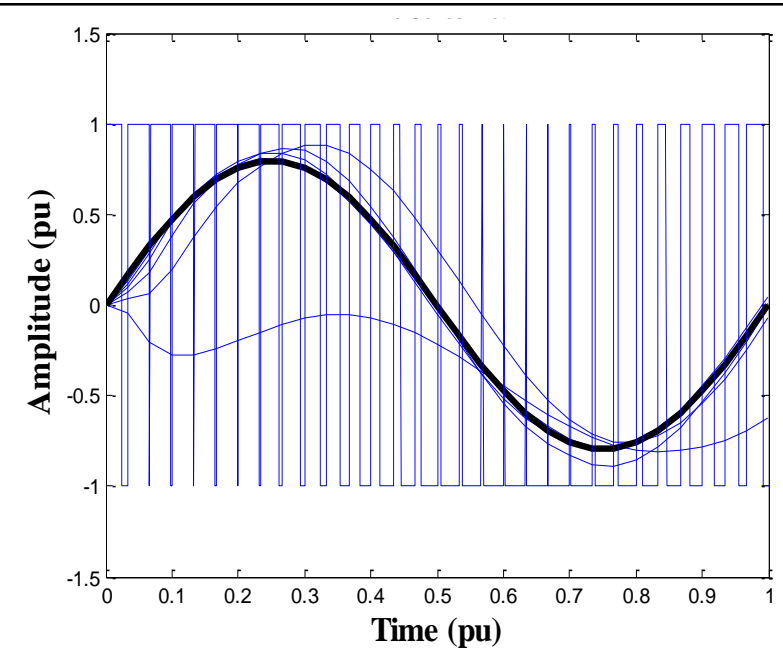

(a)

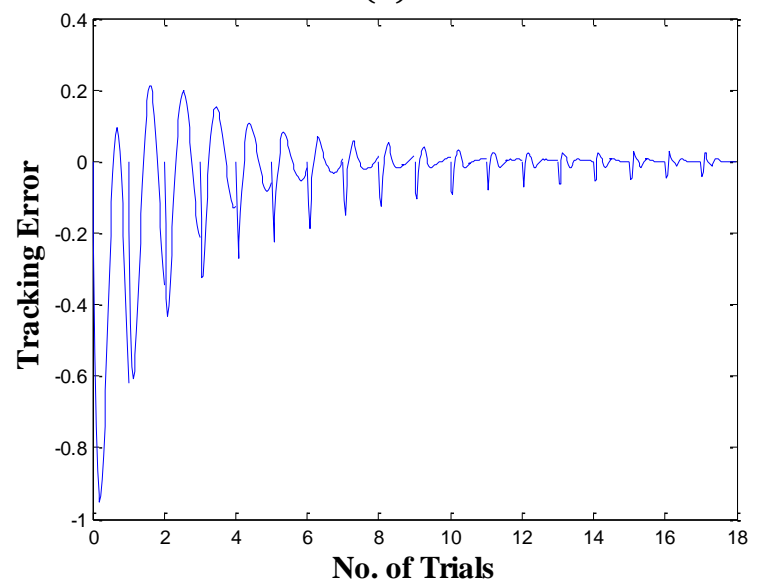

(b)

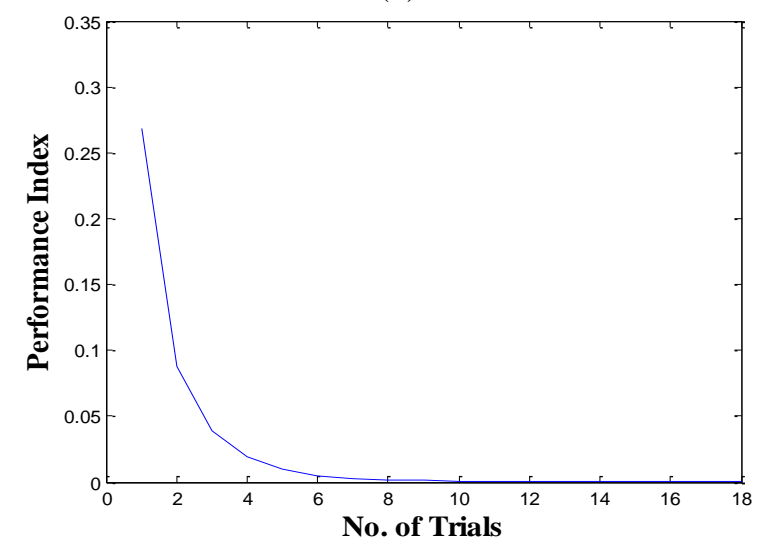

(c)

Fig. (7): PD-PSO type, learning algorithm:

(a) $i_{k}(t), i_{d}(t)$ with switching signal, (b) Tracking error, (c) The performance index. 


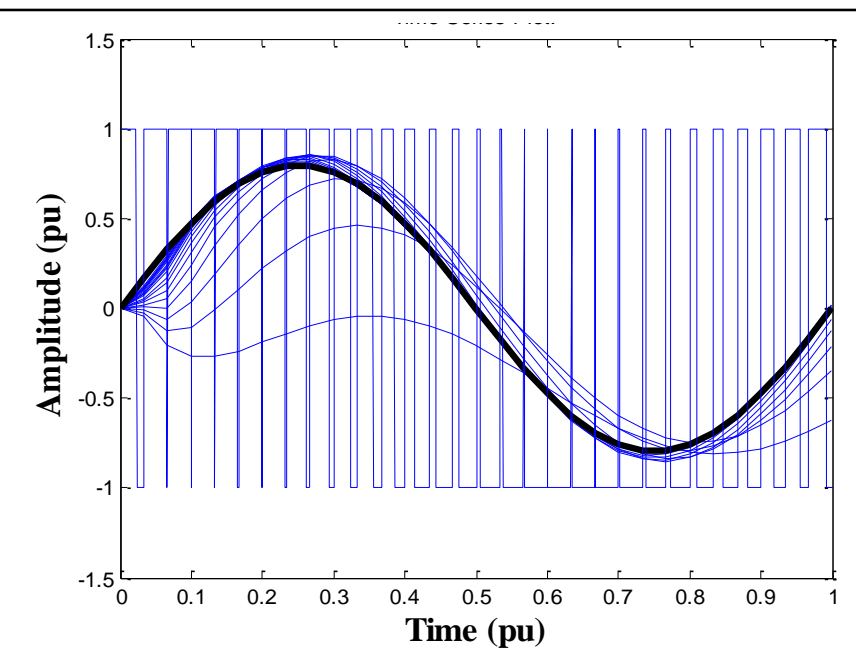

(a)

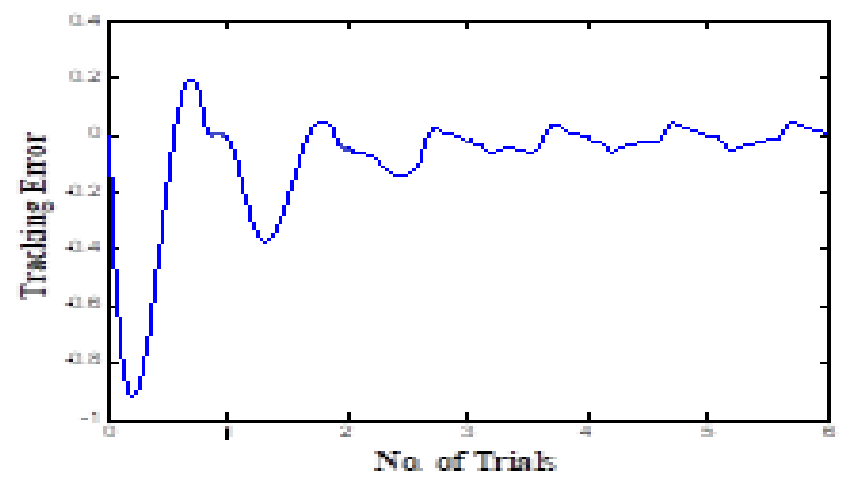

(b)

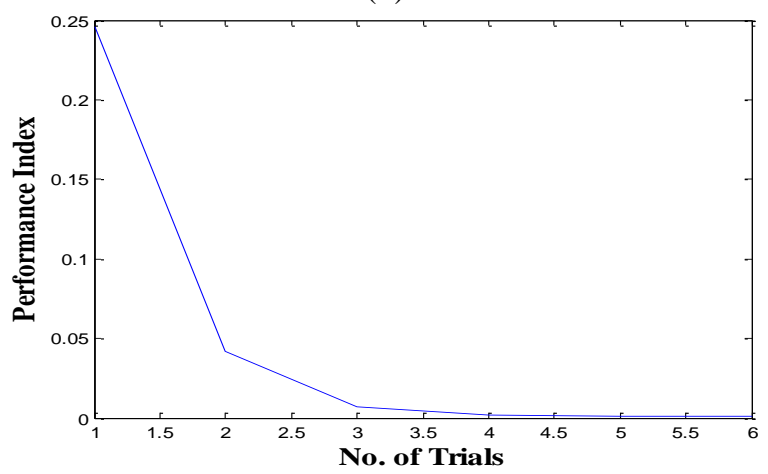

(c)

Fig. 8: PD-PSO, type, learning algorithm with load variation: (a) $i_{k}(t), i_{d}(t)$ with switching signal, (b)

Tracking error, (c) The performance index.

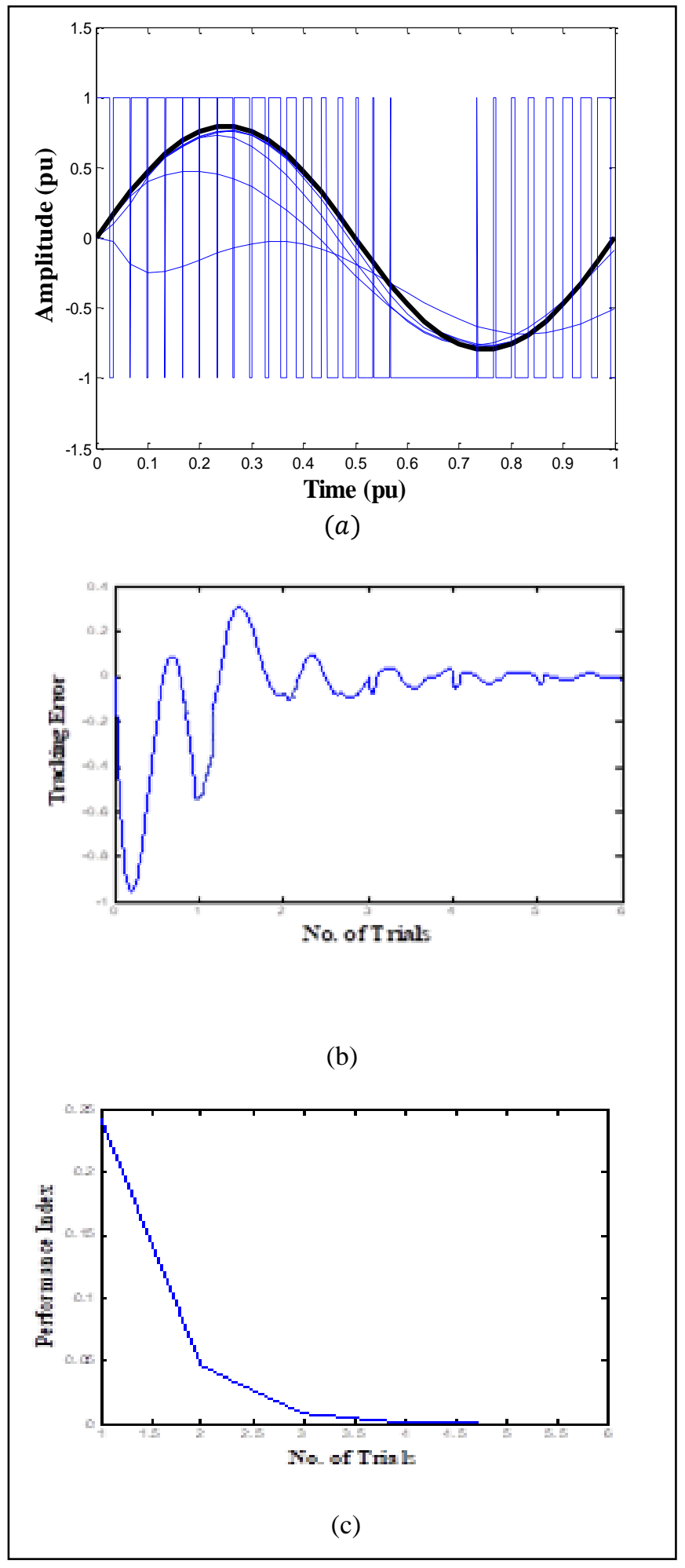

Fig. 9: PD -PSO Type controller results with source disturbance: (a) $i_{k}(t), i_{d}(t)$ with switching signal, (b) Tracking error, (c) The performance index. 
[9] T. Y. Abdulla, "Robust learning control of robot manipulators using internal model", PH. D Thesis, Basrah University, May, 2000.

[10] I. Lim, and K. L. Barton," Pareto iterative learning control: Optimized control for multiple performance objectives", Control Engineering Practice, Elsevier, February 2014.

[11] M. Mailah," Intelligent active force control of a rigid robot arm using neural network and iterative learning algorithms", Ph. D thesis, University of Dundee, Dundee, July, 1998.

[12] K.M. Omran, A. Salman, T. U. Abdulla," Higher order learning control algorithms", Basrah journal for science, vol. 6, 2006.

[13] M. Arslan, A. ul Nabi, A. Raza "Improved PID and Repetitive Control for Single Phase Inverters of Photovoltaic Power System" Engineering science and Technology International Research Journal vol.2.no.4, Dec, 2018.

[14] D. Meng and J. Zhang," Optimization-Based Learning Control for Nonlinear Time-Varying Systems", Electrical Engineering and Systems Science, arXiv:1908.02447v1, August 2019.

[15] D. Zhang and B. Wei," On the Development of Learning Control for Robotic Manipulators", Robotics, MDPI, September 2017.

[16] I. Ghasemi, A. R. Noeim and J. Sadati" Intelligent fractional order iterative learning control using feedback linearization for a single-link robot", Iium Engineering Journal, vol.18, no.1.2017.

[17] K. M. Omran," Learn ability of skilled motion for robot systems with internal model", Basrah science magazine, 30vol-2 no. 2 A, 2012.

[18] J. A. Roseline, M. S. Kumaran, V. Rajini," Generalized space vector control for current source inverters

and rectifiers", Archives of electrical engineering, vol. 65 (2), pp. 234-248, 2016.

[19] D. A. Patel, and A. R. Patel," Current source inverterFED AC machine drive system", Journal of information, knowledge and research in electrical engineering, vol. 02, Issue 02, pp. 387, Oct. 2013.

[20] M. S. Hamad, and K. H. Ahmed," A multi-functional current source inverter control for wind turbine grid interfacing", International Conference in Renewable Energy research and application, ICRERA, IEEE conference publications, pp 1328-1331, 2015.

[21] K. H. Hasan," Learning controls technique for PWM inverter, MSc. Thesis, Basrah University, 1999.

[22] C. A. Desoer and M. Vidyasagar" Feedback system input-output properties" Academic, press, ITNC. London, 1975.

[23] S. R. Bowes and R. I. Bullough "PWM switching strategies for current fed inverter drives" IEEE proc. vol. 131, no. 5, pp 195-202, 1984.

[24] P. Enjeti, J. F. Lindsay, P. D. Ziogas and M. H. Rashid," New current control scheme for PWM inverter" IEEE proc. vol.135 pt. B, no.4, pp.172-179, July 1988.

[25] Y. Yin and Y. Wu," A low harmonic electric drive system based on current source inverter", IEEE trans. Ind. Appi. vol.34, no.1, pp. 227-577, Feb 1998.
[26] B. R. G. Harley, G. Diana and J. L. Rodgerson," Implementation of a neural network to adaptively identifying and control VSI-fed induction motor stator current", IEEE Trans. on Ind. Appl. vol. 34, no. 3, pp 312-324, June 1998. [27] Russell, and J. Kennedy," A new optimizer using particle swarm theory, In Micro Machine and Human Science", MHS 95, Proceedings of the six International Symposium on, pp. 39-43. IEEE, 1995.

[28] A.T. Sadiq, F. A. Raheem, Noor A. F. Abba, Robot Arm Path Planning Using Modified Particle Swarm Optimization based on D* algorithm, AL-Khwarizmi Engineering Journal, Vol. 13, No. 3, pp. 27- 37, 2017.

[29] I. S. Fatah, "PSO-Based tuning of PID controller for speed control of dc motor", Diyala Journal of Engineering Sciences, Vol. 07, No. 03, September, pp. 65-79,2014.

[30] H.M. Rabie," Particle swarm optimization and grey wolf optimizer to solve continuous p-median location problems", proceeding of the international conference on advanced intelligent systems and informatics, springer, $\mathrm{pp}$ 136-146, April ,2020. 